\title{
Information Quality: The Relationship to Recruitment in Pre-Tertiary IT Education
}

\author{
Kaylene Clayton \\ Griffith University, Brisbane, Australia
}

K.Clayton@griffith.edu.au

\begin{abstract}
Iivari and Ervasti's (1994) Construct for User Information Satisfaction is used within a case study to examine information quality and the satisfaction of the students, teachers and guidance officers with curriculum and career guidance information. It was found that there are curriculum quality differences and dissimilar levels of IT resources available between schools. Independent school students had access to additional IT subjects and information, which enabled them to make a more informed decision about studying IT in higher classes or tertiary institutions. Independent school students were also better equipped to enter elective IT subjects in Years 11 and 12, having gained the foundations of the knowledge in earlier years. Finally, there was general dissatisfaction amongst the students with the educational experience and problems with the ability of teachers and guidance officers being able to remain current about new technologies and the changes in job descriptions in the IT industry.
\end{abstract}

Keywords: IT Education, Information Quality, Curriculum, Career Guidance

\section{Introduction}

"As a general rule, the most successful man in life is the man who has the best information.” Benjamin Disraeli (1804-1881)

The decisions that pre-tertiary students make regarding their future study and career paths will subsequently affect their place in society as well as their earning capacity. When making these choices, it is important for the students to be well informed and receive quality information within the pre-tertiary curriculum regarding IT career opportunities. There is a chronic shortage of skilled Information Technology (IT) staff, as well as constant changes in the skill mix required in the industry (Newmarch, Taylor-Steele \& Cumpston, 2000; Trauth, 2002; Young, 2002). “A paradox - especially in advanced nations - is that the IT sector that builds, maintains, empowers and enhances the infrastructure and applications is finding it hard to fill the jobs it creates” (Multimedia-Victoria, 2001). Moreover, the number of students choosing to undertake higher studies in IT is not growing at the same rate as with other degree or study programs (Beekhuyzen, Nielsen \& von Hellens, 2003; Gürer \& Camp, 2002).

This study will be of an interpretive nature and uses an anti-positive epistemology and ideo-

Material published as part of this journal, either on-line or in print, is copyrighted by Informing Science. Permission to make digital or paper copy of part or all of these works for personal or classroom use is granted without fee provided that the copies are not made or distributed for profit or commercial advantage AND that copies 1) bear this notice in full and 2) give the full citation on the first page. It is permissible to abstract these works so long as credit is given. To copy in all other cases or to republish or to post on a server or to redistribute to lists requires specific permission from the publisher at Publisher@InformingScience.org graphic methodology to explore the quality of, and subsequent satisfaction with, curriculum and career guidance information provided to pre-tertiary students. It seeks to answer the question 'What is the relationship that curriculum and career guidance information quality in pre-tertiary education 
Information Quality: The Relationship to Recruitment in Pre-Tertiary IT Education

has to recruitment to tertiary IT education?' A review of literature concerning Information Systems (IS) success, in particular, information quality and User Information Satisfaction (UIS), is performed. A case study is then used to explore the complexity of the topic and draw insights into the effect of information quality on tertiary IT education enrolment.

In the context of this study, the definition of an IS has been derived from two previous classic definitions by Ives, Hamilton and Davis (1980) and Keen (1980) and is as follows. An IS is the study of the problems of effective and ethical design and implementation of systems and the influences and impacts that they have in organizational, societal and individual contexts. This IS "creates information which is communicated to the recipient who is then influenced (or not!) by the information” (DeLone \& McLean, 1992).

Quality is a difficult to define, “complex and multifaceted concept” (Garvin, 1984). In Garvin's (1984) user-based definition of quality, individuals have different wants and needs, and it is believed that quality "lies in the eyes of the beholder". It is this highly subjective user-based quality view that will be taken within this paper. According to Vandenbosch and Higgins (1995), there is a strong relationship between quality and use or success and "it would appear that the higher the quality of the system, the greater the possibility that it will promote learning”. Information quality can be studied for the desired characteristics such as accuracy, meaningfulness and timeliness (DeLone \& McLean, 1992). Subsequently, UIS is a perceptual or subjective measure of "the extent to which users believe the information system available to them meets their information requirements” (Ives, Olson \& Baroudi, 1983).

This paper provides an overview of relevant literature related to IS quality and recruitment of pretertiary IT students in the Information Systems Quality Section. In the following section, the research design and setting for this study is then outlined and justified. A presentation and discussion of the findings of this exploration follows in the Findings Section. The article concludes with a summary of the relationship of information quality to recruitment of pre-tertiary IT students and future directions for research.

\section{Information Systems Quality}

According to Swanson (1997), "IS are socio-technical processes involving both humans and machines (computers)" and "they become organizationally embedded in their use". Stylianou and Kumar (2000) believe that "IS quality is the perceived quality of IS products and services in the eyes of stakeholders.” Organizational factors such as politics, culture and senior management support, are variables, which may affect the impact of organizational investments in IT on IS quality (Stylianou \& Kumar, 2000).

"IS quality is made manifest in use and cannot be attained through a perspective that is wholly production-oriented” (Vidgen, Wood-Harper \& Wood, 1993). Furthermore, Eriksson and Torn (1991) state that "IS use quality is used to cover all aspects of how well the system serves the user" and that "benefits arise from IS use". However, "no outcome is wholly positive” (DeLone \& McLean, 2002). It is the differences between costs and benefits that determines the general usefulness of an IS and in general high utility means low costs and high benefits (Eriksson \& Torn, 1991). Moreover, Eriksson and Torn (1991) state that it cannot be said that a product with good internal properties but with a low utility is of a high quality.

One important issue related to IS use quality is what the system does for the user and the IS should be designed to meet user needs along with being augmentable and secure (Eriksson \& Torn, 1991). Each IS user group is very heterogeneous and needs to be identified separately for each system and within each organization (Eriksson \& Torn, 1991). These groups are the people that are responsible for and primarily interested in use quality (Eriksson \& Torn, 1991). Having 
multiple stake-holders with different perspectives means that the "definition of use quality (the 'ends') is just as problematical as the management of quality (the 'means')” (Vidgen et al., 1993).

Checkland and Scoles (1990, p. 1) define five criteria (the 5Es) for judging the success of a transformation, which include efficacy, efficiency, elegance, effectiveness and ethicality. Vidgen, et al. (1993) states that the "use of the 5Es allows debate to focus on what constitutes quality, (a successful transformation) in the human activity system and then talk about what quality factors and metrics might reflect the notion of use quality in the 'real world'." Yet, because of differences in quality perception, variations in systems will be required by people with different learning preferences and cognitive styles to achieve the same level of use quality satisfaction (Lindroos, 1997). However, "use, especially informed and effective use, will continue to be an important indication of IS success” (DeLone \& McLean, 2002). DeLone and McLean's (2002) reformulated IS success model describes the linkages between use and user satisfaction in relation to information, system and service quality (Figure 1).

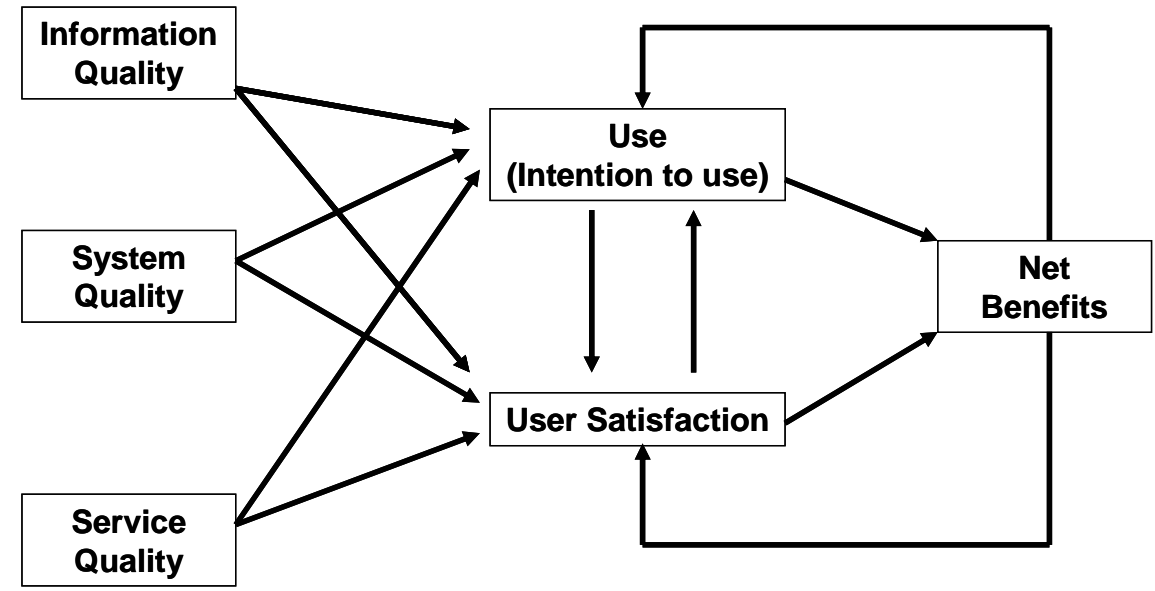

Figure 1: DeLone and McLean’s (2002) Reformulated IS success model

\section{Information Quality}

Information can be defined as "data that have been processed into a form that is meaningful to the recipient and is of real or perceived value in current or prospective decisions" (Davis, 1974, p.32 cited in Vandenbosch \& Higgins, 1995). This information, whether it is a message in a communication system or the output of an IS, can be measured at different levels including the semantic, technical and effectiveness levels (DeLone \& McLean, 1992). Furthermore, Emery (1971, p.1 cited in DeLone \& McLean, 1992) states that "information has no intrinsic value; any value comes only through the influence it may have on physical events. Such influence is typically exerted through human decision makers”.

DeLone and McLean (2002) state that information quality and system quality, are the most important quality components to measure the success of an IS in an organization. As part of their everyday life, people at all levels of organizations, make decisions that affect themselves or other people (Denby \& Gammack, 1999). Thus, the quality of an IS needs to be assessed in the context of organizational members and their work practices by assessing how well their everyday information needs are satisfied" (von Hellens, 1997). Assessment of information quality "is concerned with such issues as the timeliness, accuracy, relevance and format of information” (Lindroos, 1997). Furthermore, Swanson (1997) states that information quality attributes include importance, relevance, usefulness, accuracy, precision, conciseness, completeness, currency amongst others. 
Information Quality: The Relationship to Recruitment in Pre-Tertiary IT Education

"Information and learning are frequently linked” (Vandenbosch \& Higgins, 1995) and Eisenberg and Small (1993) believe that "in both formal and informal educational situations, the quality of information is essential.” Many people, including educators, are concerned about the "role and impact of information on people and environments, technologies, systems, and skills" (Eisenberg \& Small, 1993). A series of events, assembled under the broad title of the information explosion, profoundly effects education and has serious implications for skills required by students, pedagogical methods and educational content (Eisenberg \& Small, 1993). Other significant issues challenging the educational research community and educators are associated with the implementation of IT, the use of information resources and the instruction of information skills in educational institutions (Eisenberg \& Small, 1993). Eisenberg and Small (1993) also state that there is "no comprehensive body of research considering the nature and impact of information in education”.

\section{User Information Satisfaction}

Ives et al. (1983) states that UIS is "the extent to which users believe the information system available to them meets their information requirements. It is a perceptual or subjective gauge of system success that functions as a surrogate for objective antecedent of IS effectiveness, which are often unobtainable (Ives et al., 1983). However, "a key issue is whose satisfaction should be measured” (DeLone \& McLean, 1992). Iivari (1996 cited in Lindroos, 1997) describes UIS as being "built up of user satisfaction, information quality and the part of the system quality concerning the user interface and usability".

UIS has potential bearing in three significant areas including realization of IS department goals, user quality of work life and degree of voluntary system usage (Galletta \& Lederer, 1989). Lindroos (1997) maintains that UIS is a group of concepts explicitly intended to gauge a user's satisfaction with the IS and associated services. DeLone and McLean (2002) believe that "use must precede user satisfaction in a process sense but positive experience with use will lead to a greater user satisfaction in a causal sense" (DeLone \& McLean, 2002). However, Iivari \& Ervasti (1994), propose that the link between UIS and IS effectiveness can be established directly without the intervening variable of IS use when UIS is understood in the sense of satisfactoriness rather than satisfaction. Reicks (2001) believes that most people want access to the right information, as they recognize that superior information and they want to make the right decisions. "Sharing the right information with the right people at the right time can empower these individuals" (Reicks, 2001).

Several models for evaluating UIS have been proposed including the Doll-Torkzadeh (1988) instrument, the Bailey-Pearson (1983) measure, and the Iivari-Koskela (1979) construct. The DollTorkzadeh instrument takes the ease of use into account, however, it measures UIS in terms of frequency of satisfaction, which implies a history of use (Iivari \& Ervasti, 1994). Iivari and Ervasti (1994) attest that the Bailey-Pearson instrument is one of the most commonly applied measures and that a subset of its scales is implicitly advocated by DeLone and McLean (1992). A subset of the Bailey-Pearson instrument, which concerns the whole IS function (Iivari \& Ervasti, 1994), corresponds with the Iivari-Koskela construct (Iivari \& Ervasti, 1994). As seen in Figure 2, the Iivari-Ervasti (1994) Construct for UIS is comprised of: 'informativeness', which embraces relevance of information structure and reliability and recentness of information; 'accessibility', which is made up of convenience of activation, response time/timeliness, and interpretability; and 'adaptability'. 


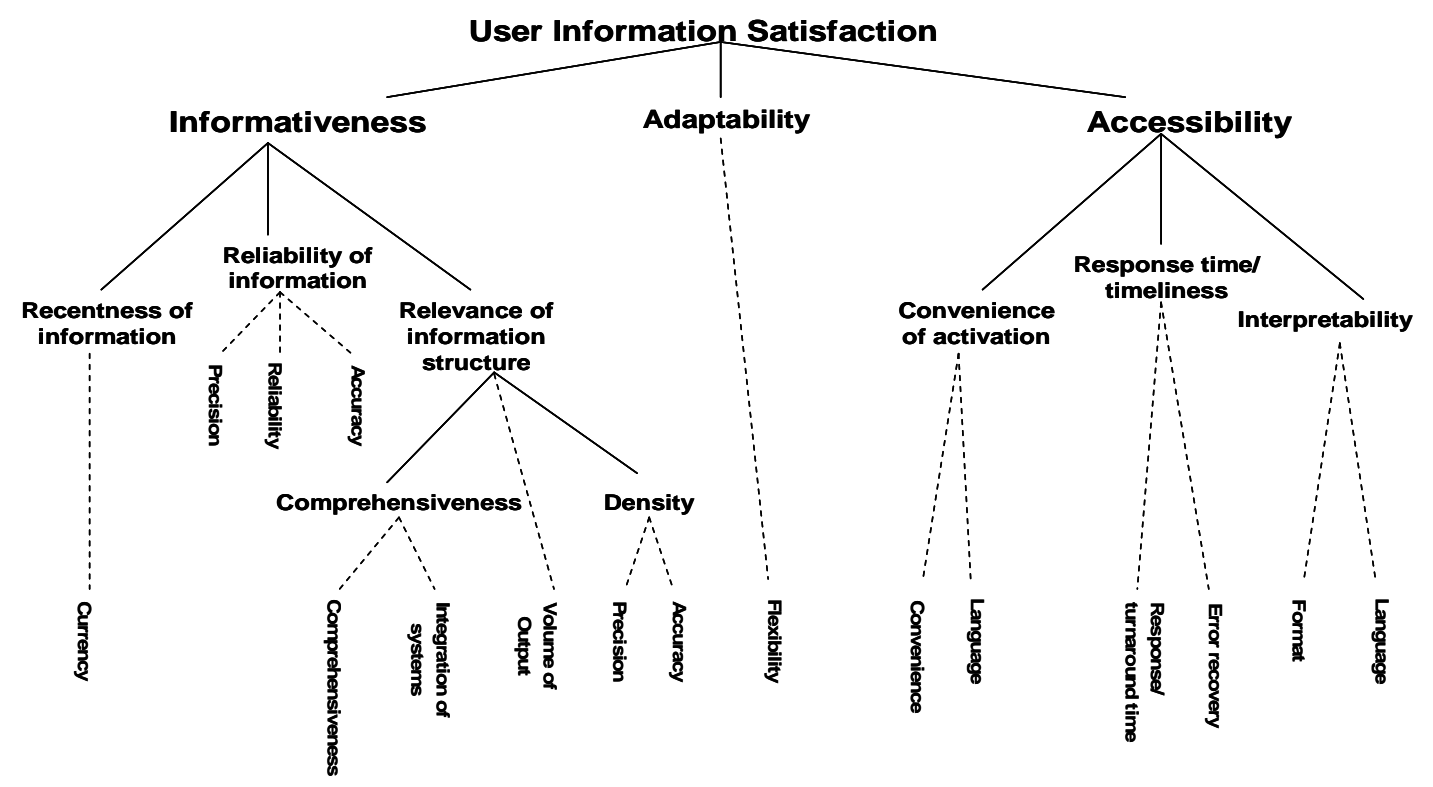

Figure 2: Iivari and Ervasti’s (1994) Construct for User Information Satisfaction

\section{Research Design and Setting}

\section{Methodology}

Ideographic approaches are “... based on the view that one can only understand the social world by obtaining first-hand knowledge of the subject under investigation" and include techniques such as case studies (Burrell and Morgan 1979, p.6). This study primarily follows an ideographic methodology to understand the area being researched by obtaining first-hand knowledge and subjective accounts from Year 9 and 12 students, educators and guidance officers at one independent and one government school in southern Brisbane. Furthermore, library research was used to provide a background to this study.

The ontological research assumption that will be taken is that of a subjective reality, as the nature of this research exists "through the action of humans in creating and recreating it" (Jarvinen, 2001). Further, the epistemological research hypothesis that will be taken is an anti-positivist assumption, as it maintains that the social world "... can only be understood from the point of view of the individuals who are directly involved in the activities to be studied” (Burrell \& Morgan, 1979). Triangulation was used to allow the blending and integration of both qualitative and quantitative data from the Year 9 and Year 12 students, teachers and guidance officers in the study of the same phenomenon.

This paper uses a subset of research data from a larger study, which investigated pre-tertiary perceptions of IT and issues involved with recruitment of students into IT programs. The scope of this paper deals with issues related to information quality and the effects that this has on student, teacher and guidance officer perceptions of IT and recruitment into IT education and career paths. Other findings from the larger study fall outside of the scope of this paper and as such, will not be discussed. 
Information Quality: The Relationship to Recruitment in Pre-Tertiary IT Education

\section{Research Site}

Two co-educational schools were chosen to participate in the research, one being a government run high school serving Year 8 to Year 12 students, and the other an independent college, catering for preschool to Year 12 students. The government school (GOV) was chosen from a mid range socio-economic area and has a population of approximately 1100 students, of which there are approximately 220 students in Year 9 and 165 students in Year 12. The mid-socio-economic GOV represents the mean of the government schools in the Southern Brisbane/Logan school area. The independent school (IND) has roughly 1100 students enrolled, with approximately 125 students in Year 9 and 100 students in Year 12. It was chosen because of its geographic closeness to the GOV allowing a comparison of computing resources and environments and whether this affects the student, teacher and guidance officer's perceptions of IT. Co-educational schools were chosen to be able to access the opinions of both genders in relation to IT.

Year 9 students were chosen for several reasons. Firstly, a review of literature showed that in general until late primary school students showed no gender difference in attitude towards computing (Dorman, 1998). Additionally, Year 9 is the first time that students are able to make elective subject choices (Young, 2002). The Year 12 students were chosen because they are about to complete their secondary education and would provide valuable information on their plans for their future study and careers. Teachers and guidance officers of these students were chosen to participate because of the direct contact that they have with these students. Guidance officers from Brisbane, the Gold Coast and Northern New South Wales attending an information session for tertiary education were deliberately targeted to participate in this study. This was done because student to guidance officer ratios at the chosen schools would only allow an extremely small sample size.

\section{Survey and Interview Methods}

The surveys for students in Years 9 and 12 comprised 25 semi-structured or dichotomous questions, as well as open-ended questions, which were used to gain insights into their perceptions of IT. The teacher survey instrument contained 24 semi-structured or dichotomous questions, as well as written open-ended questions directed at areas relating to curriculum and delivery of teaching material and professional support systems for the teacher. The guidance officer survey instrument contained 18 questions asked in a similar style to the teacher surveys in areas relating to IT career guidance information. Within the IND and GOV, 305 and 445 surveys were distributed respectively with corresponding return rates of 56 and 64 percent. Fifty guidance officer surveys were distributed with a 75 percent return rate.

One male and one female teacher at each school were interviewed. Difficulties in obtaining female teaching participants were encountered as some IT departments did not have any female staff members. Consequently, the female teachers interviewed in this study did not work in their school's IT department, however, they had strong ties to technology and teaching. One female and one male Year 12 student were interviewed at each school. These students were either currently enrolled in IT subjects or had previously been enrolled in an IT subject. Difficulties in obtaining consent for interviews were encountered with the Year 9 GOV students. Consequently only one male and one female Year 9 student was interviewed at the IND. In the findings, the survey respondents will be referred to as Respondent 1 - 496 and the students and teachers who were interviewed will be referred to as S1 - 6 and T1 - 4 respectively.

\section{Findings}

Within this section Iivari and Ervasti's (1994) Construct for UIS, as previously described, is used to examine the data collected within the case study. In this instance it will be used to examine 
information quality and the satisfaction of the students, teachers and guidance officers with this information. DeLone and McLean (1992) reaffirm this relationship in the statement "the information system creates information which is communicated to the recipient who is then influenced (or not!) by the information”. However, components of this construct that are fundamentally involved in measuring the UIS of an IS, such as Relevance of Information Structure, will not be investigated. The dimensions of this model that are concentrated on include Informativeness with particular attention to recentness and reliability of information and Accessibly in terms of interpretability. These factors concentrate on the content of the information system and the manner in which the information is presented (Ives et al., 1983).

\section{Informativeness}

"Informativeness describes the potentiality of the data system as a producer of information for the user in question" (Iivari \& Koskela, 1979). The two areas within informativeness that will be concentrated on are reliability and recentness of information. These areas include factors such as precision, reliability, accuracy and currency (Iivari \& Ervasti, 1994).

According to the Telecom Glossary 2000 (ATIS, 2001), precision refers to the ability to reproduce the same result when given the same input in the same environment. Precision in the case of this study refers to the ability of the system to provide consistent sharing of career guidance and subject information between the differing groups including Year 9 and 12 students and independent and government school students. Whilst the Year 9 and 12 students attending the same school share the same environment, other schools have differing environments.

Schools are required to teach a certain amount of core information, but the way that this information is taught may differ to a certain degree from school to school and teacher to teacher. An example of this was seen when teachers were asked whether the IT curriculum adequately prepares students for students for further study or placement in the IT workforce: "Depends which school" (Respondent 435). Independent schools may have more freedom in delivering the curriculum than government schools have because of not being a part of the government system. Also, some schools are resourced better than other schools, even within the government sector, which can be seen in a comment from a GOV teacher.

“...We could get more money if we charged higher fees, which some of the schools do. But we have elected to keep our fees at a reasonable level, which means that our technology may suffer. But I don't think ... our kids really suffer. I mean the basic stuff is there available for what they need to do. We don't have the flash stuff like some of the schools might have...." (T2)

A GOV teacher also commented about the differences between the amount of computing resources that were expected and the amount of resources that they could afford to supply.

"Well they want us to have a 1:5 ratio in the school computers for students ... that gives me a 1:250 ratio or a 1:300 computer ratio including staff... That is well outside of industry expectations and possibilities..."(T2)

Other deviations in the IT curriculum available between independent and government schools were found. The IND offers Computer Studies as a compulsory subject in Year 8 and as an elective subject in Years 9 and 10 as well as Information Processing and Technology (IPT) and Information Technology Systems (ITS) electives in Years 11 and 12. The GOV however, did not offer the Computer Studies (or comparable subject) either as a compulsory or elective subject in Years 8, 9 or 10. It did offer IPT and ITS as an elective subject in Years 11 and 12. When the IND students were asked about being enrolled in the Computer Studies class and the effect that it had on decisions to study IPT in Years 11 and 12 the response was: ".. get to know which ones 
Information Quality: The Relationship to Recruitment in Pre-Tertiary IT Education

you would like rather than going, yeah, I will have that one and you don't know what it is like. So if you do it in Years 8, 9 and 10 you understand what you can do.” (S4). A GOV student who dropped out of IPT also commented on the difficulty of not having an IT subject in earlier schooling: “...you do maths from Grade 1, but you don't do computer programming from Grade 1. You don't know what you are walking into." (S2)

The comparison of these two comments implies that students at the IND had more information available to them about IT that would enable them to make an informed decision about studying IT in higher classes or progressing to tertiary studies. It also implies that the students at the IND are better equipped to enter IPT in Year 11 and 12, having gained the foundations of the knowledge for IPT in earlier years. This statement was confirmed by an IND student's comment: “... in Year 9 we do web pages and in Year 10 we do programming and that whole last semester of programming is like an introduction to IPT."(S6)

To increase the precision aspect of information quality in relation to pre-tertiary IT education and subsequently UIS, the school environment and curriculum would need to be standardized between all schools. In an ideal world, government and independent schools and both systems as a whole would agree upon and adopt the same IT curriculum and have the same resources available to pre-tertiary students. This would include all schools having a Computer Studies subject, or equivalent, available in Years 8, 9 and 10 as well as having a similar IPT/ITS curriculum in Years 11 and 12. Also, computer resources, such as student to computer ratios, support and teaching staff would ideally need to be equally available to the students in all schools, both government and independent. This would assist pre-tertiary students in making a more informed decision about whether to go on to do tertiary studies in IT.

Reliability implies that the "information provided is accurate (updated), valid and credible" (Kim, 1999) and accuracy of information refers to "information that is correct, free of errors and relevant for information consumers" (Matsumura \& Shouraboura, 1996). Currency of information relates to the general acceptance of the information in relation to the present time and is related to accuracy of the information. These three interrelated items fall under the banner of Reliability of Information (Iivari \& Ervasti, 1994) and are sometimes difficult to separate.

Students attend school to learn accurate information, and teachers strive to teach accurate information within their pedagogy. Teachers are expected by society to have a wide range of knowledge, skills and ability in their area of teaching and within their context. However, for IT teachers, the extreme rate of change that is associated with the IT industry creates problems with the ability of teachers being able to remain current. This was commented on by both guidance officers and GOV teachers.

"Because of the rapid changes in the world of IT, it is an effort to keep abreast of the changes occurring.” (Respondent 11)

and "...I think in terms of teaching it [IT] I think that it needs more preparation time because things change so rapidly. I don't think people above appreciate that. I could go back to teaching chemistry tomorrow and yes, the syllabus has changed fractionally, but the basic chemistry hasn't changed in 50 years and the level we teach at high school won't change. "(T2)

Teacher responses in this study parallel a finding made in the Reality Bytes Report (MultimediaVictoria, 2001), which reports that "teachers indicate that it is difficult to keep the curriculum up to date with the rapid developments that characterise IT". When discussing the quality of the curriculum a GOV teacher and an IND IT teacher with an IT background replied:

"I think IPT, the subject, is a bit out of date, but it is going through a change right now. So hopefully we will improve its relevancy. The thing is that we are too focused on a 
small segment of computing rather than the broader things it could be ... I don't think we can keep up with it. I don't know what the answer is going to be in relation to what curriculum we are going to offer". (T2).

and "... I am not too sure how up to date it [the IT curriculum] is. We try, but it is always hard to know which way to go and there are so many ways. ... the quality might also be limited by the texts that we have. They quickly go out of date.” (T4).

According to Young (2003) "a reasonable assumption to make is that if students find a subject interesting, then it is more likely that they will achieve well in it”. However, there was general dissatisfaction with the educational experience. A large number of students felt that it was boring, that there was too much to learn and that there was too much theory and not enough practical work: "The theory is boring and you do more of that" (Respondent 215) and "It's sometimes boring because of the teacher" (Respondent 186).

Another finding within the case study was that the IT teachers interviewed stated that IT was not their first teaching preference and that they began teaching in the area out of organizational need.

"I arrived in my second school as a third year teacher and the computer teacher had gone away on leave for 6 or 12 months. They said that 'You're young, here is the computer room. You are teaching the class tomorrow. Here you go.' And that was my first introduction to computers. I walked in and asked the kids how to turn them on. The kids thought [that] I was joking." (T2)

The need for qualified teaching staff was also identified by teachers. One teacher commented about IT teacher levels by stating that: "There [is] not enough qualified staff teaching the subject ...” (Respondent 493). The teacher concern in this case study supports findings in the Reality Bytes report (Multimedia-Victoria, 2001), which states that: “... the curriculum is failing to engage students and that considerable efforts are needed to support IT teachers through professional development”.

Another difficulty that guidance officers and teachers face is to do with the changes in job descriptions in the IT industry. Within this case study, 73 percent of guidance officers acknowledged that it was difficult to remain current about skills required for IT careers. Furthermore, only 16 percent of guidance officers believed that they were very informed about IT careers. One comment from a guidance officer was, “I am an IT bunny - don't know much” (Respondent 31). The Reality Bytes report (Multimedia-Victoria, 2001) states that pre-tertiary students want IT career information with regard to "the types of jobs, the skills required and remuneration". If guidance officers are not well informed about IT careers, it is difficult to understand how they could give accurate, current and reliable IT career information to students.

When the students and teachers were asked to describe what an IT professional did as part of their daily routine, there was an overwhelming student response stating that they had no idea or simply, that IT professionals work on or with a computer. Some of the teachers also responded in a similar manner. There were also responses from Year 12 students such as "I don't really have any idea what Information Technology is" (Respondent 407) and "I've been told that IT is not such a good career as you have to always update your knowledge, so you have to pay a lot for further study frequently" (Respondent 345). The problem with this last comment is that it is not only within the IT industry that workers have to update their knowledge, most careers, such as nursing or teaching, as well as blue collar industries require this. These comments highlight the students very poor understanding of what working within the IT industry involves and the opportunities or careers available and confirm Young's (2002) findings that "high school students in Australia have a minimal understanding of IT careers. 
Information Quality: The Relationship to Recruitment in Pre-Tertiary IT Education

"Students approaching the end of secondary schooling face major decisions about their future vocations and choice of tertiary study" (Sheard, Lowe \& Markham, 2001). These students need to be given reliable and accurate information to help make informed decisions about their future careers. In 1998, over 25 percent of female undergraduate students surveyed at Southern Cross University indicated that they had been "misinformed and that, with better information, they might have considered an IT degree” (Jewell \& Maltby, 2001). Moreover, one GOV student commented about the career guidance information given by their guidance officer, "... The non judgmental thing got in the way of trying to help you." (S1). The Reality Bytes report (Multimedia-Victoria, 2001) found that teachers often felt uncomfortable or lacked confidence to offer career advice to students with many saying that they "did not have access to accurate information". Litigation may be one reason why teachers and guidance officers are cautious in giving career guidance information. The following teacher comment was recorded during a discussion about IT career advice.

"We have to be careful that we don't tell them what to do, because they can later come back at you and sue you for giving wrong advice. I would just make them aware of the job prospects ..." (T4)

\section{Accessibility}

According to Iivari and Koskela (1979) "accessibility of the information describes the quality of the user-data system communication". There are three sub areas related to accessibility in the Iivari and Ervarti (1994) UIS Construct. These include Convenience of Activation, Response time/timeliness and Interpretability. Interpretability "is the extent to which information is in appropriate languages, symbols, and units and the definitions are clear” (Kahn, Strong \& Wang, 2002). Interpretability consists of two secondary factors, language and format. The Telecom Glossary 2000 (ATIS, 2001) defines language as "a set of characters, conventions, and rules that is used for conveying information" and format as the arrangement of these characters or the "shape, size, and general makeup of a document". This section concentrates on the language quality factor, which will be used in regards to the understandability of language.

As within many occupations, IT contains its own occupation specific language and to be useful to people this language must be able to be understood. Some of this language is not well known, whilst other parts are becoming accepted into everyday language. An example of this can be seen in the comment: “... stare@ @ the] screen” (Respondent 393). Ten years ago, the @ symbol would not have been recognized and used, except in a technical context. However, because of increasing Internet use, it is now being absorbed into everyday language as shorthand for "at". Throughout the analysis of the case study data, it became apparent that the students did not appear to have any difficulty understanding the language involved in IT. Yet, a difficulty that guidance officers and teachers face is to do with the amount of jargon in the IT industry. "Careers advisers admitted to finding the industry extremely confusion - once again jargon is a problem" (Standley \& Stroombergen, 2001). Within this case study, 86 percent of guidance officers agreed that it was challenging to keep pace with changes in IT jargon and 76 percent of teachers surveyed agreed that it was difficult to understand IT jargon.

\section{Conclusion}

Through the analysis of the data, it was evident that there are differences in the quality of the curriculum between schools. Even those within the government sector have disparate levels of resources available for use in the IT curriculum. It was found that the IND students had access to more information related to IT studies than the GOV students did, and that this information enabled them to make an informed decision about studying IT in higher classes or going on to tertiary studies. It also implies that the students at the IND are better equipped to enter IPT in Year 11 
and 12, having gained the foundations of the knowledge for IPT in earlier years. Furthermore, in this case study it was seen that there was general dissatisfaction amongst the students with the IT educational experience, expressed with comments such as IT subjects are boring and that there was too much theory and not enough practical work involved.

The need for qualified IT teaching staff was also identified by teachers. A number of IT teachers in this case study also stated that IT was not their first teaching preference and that they began teaching the subject only out of organizational need. Also, for IT teachers and guidance officers, the extreme rate of change that is associated with the IT industry creates problems with the ability of teachers and guidance officers being able to remain current about new technologies and the changes in IT job descriptions. Moreover, the majority of guidance officers acknowledged that it was difficult to remain current about the ever changing IT careers and only 16 percent of guidance officers believed that they were very informed about IT careers. If guidance officers are not well informed about IT careers, it is difficult to understand how they could give accurate, current and reliable IT career information to students that would encourage them into IT study or careers. This was demonstrated when the students were asked to describe what an IT professional did as part of their daily routine and there was an overwhelming response ranging from stating that they had no idea to just simply working on or with a computer.

All of these identified factors relating to IT curriculum and career guidance information contribute to low enrolment in IT subjects and subsequently tertiary IT study. Findings from this analysis established that the lack of or poor quality IT information leads to poor perceptions of IT and that both teachers and guidance officers need assistance to help them remain current in curriculum, industry and careers information. Students need to have access to high quality, accurate, reliable and current information to break the cycle of poor perceptions of IT so that they can make informed decisions and perhaps encourage IT enrollments.

This research was limited as only two co-educational schools in similar mid socio-economic areas were chosen to participate. Further research projects should include single sex schools in differing socio-economic regions and include significant people in the student's life such as parents and siblings. Future research in this area is warranted due to the importance of the relationship between this problem and the chronic shortage of skilled IT personnel. These students are the potential IT personnel of the future and if they cannot make an informed decision about IT careers, the IT industry may be losing a wealth of potential contributions. Future research may be able to identify ways in which the information provided within the IT curriculum could be changed to make it more dynamic and appealing. This could be achieved through further case studies involving both students and teachers. Other areas of research that are required in this area include investigating through case studies how career guidance information is best shared between students, teachers and guidance officers and the different mediums that would allow the most reliable and widespread dissemination of this information.

\section{References}

ATIS. (2001). Telecom glossary 2000. Retrieved October 10, 2003, from http://www.atis.org/tg2k/

Bailey, J. E. \& Pearson, S. W. (1983). Developing a tool for measuring and analyzing computer user satisfaction. Management Science, 29 (5), 530-545.

Beekhuyzen, J., Nielsen, S. H. \& von Hellens, L. A. (2003). Challenging dualisms in female perceptions of IT work. Australian Journal of Information Systems, 10 (2), 105-115.

Burrell, G. \& Morgan, G. (1979). Sociological paradigms and organisational analysis: Elements of the sociology of corporate life. London: Heinemann.

Checkland, P. \& Scholes, J. (1990). Soft systems methodology in action. Chichester: Wiley. 
Information Quality: The Relationship to Recruitment in Pre-Tertiary IT Education

Davis, G. B. (1974). Management information systems: Conceptual foundations, structure and development. New York: McGraw Hill.

DeLone, W. H. \& McLean, E. R. (1992). Information systems success: The quest for the dependent variable. Information Systems Research, 3 (1), 60-95.

DeLone, W. H. \& McLean, E. R. (2002). Information systems success revisited. Proceedings of the 35th Hawaii International Conference on System Sciences, Island of Hawaii (Big Island).

Denby, E. \& Gammack, J. (1999). Modelling ignorance levels in knowledge-based decision support. Proceedings of 2nd Western Australian Workshop on Information Systems Research, Perth.

Doll, W. J. \& Torkzadeh, G. (1988). The measurement of end-user computing satisfaction. MIS Quarterly, 12 (2), 259-274.

Dorman, S. M. (1998). Technology and the gender gap. Journal of School Health, 68 (4), 165-166.

Eisenberg, M. B. \& Small, R. V. (1993). Information-based education: An investigation of the nature and role of information attributes in education. Information Processing \& Management, 29 (2), 263-275.

Emery, J. C. (1971). Cost/benefit analysis of information systems. SMIS workshop report number 1, The Society for Management Information Systems, Chicago.

Eriksson, I. \& Torn, A. (1991). A model for IS quality. Software Engineering Journal, 6 (4), 152-158.

Galletta, D. F. \& Lederer, A. L. (1989). Some cautions on the measurement of user information satisfaction. Decision Sciences, 20 (3), 419-438.

Garvin, D. A. (1984). What does "product quality" really mean? Sloan Management Review, 26 (1), 2-43.

Gürer, D. \& Camp, T. (2002). Investigating the incredible shrinking pipeline for women in computer science -Final Report (version 4), Retrieved February 16, 2003, from http://www.acmw.org/documents/finalreport.pdf

Iivari, J. \& Ervasti, I. (1994). User information satisfaction: IS implementability and effectiveness. Information \& Management, 27, 205-220.

Iivari, J. \& Koskela, E. (1979). Choice and quality criteria for data system selection. Proceedings of EuroIFIP79, European Conference on Applied Information Technology, Amsterdam.

Ives, B., Hamilton, S. \& Davis, G. B. (1980). A framework for research in computer-based management information systems. Management Science, 26 (9), 910-934.

Ives, B., Olson, M. H. \& Baroudi, J. J. (1983). The measurement of user information satisfaction. Communications of the ACM, 26 (10), 785-793.

Jarvinen, P. (2001). On research methods. Tampere, Finland: Juvenes-Print.

Jewell, H. \& Maltby, J. R. (2001). Female involvement in information technology degrees: Perception, expectation and enrolment. Proceedings of the Twelfth Australasian Conference on Information Systems, Coffs Harbour, NSW.

Kahn, B. K., Strong, D. M. \& Wang, R. Y. (2002). Information quality benchmarks: Product and service performance. Communications of the ACM, 45 (4), 184-192.

Keen, P. G. W. (1980). MIS research: reference disciplines and a cumulative tradition. Proceedings of the First International Conference on Information Systems, Philadelphia, Pennsylvania.

Kim, E. (1999). A model of an effective web. Americas Conference on Information Systems, Milwaukee, Wisconsin.

Lindroos, K. (1997). Use quality and the World Wide Web. Information and Software Technology, 39 (12), 827-836.

Matsumura, A. \& Shouraboura, N. (1996). Competing with quality information. International Conference on Information Quality, Cambridge, Massachusetts. 
Multimedia-Victoria (2001). Reality bytes, Victorian Government. Retrieved March 31, 2003 from, http://www.mmv.vic.gov.au/cvnewsletter

Newmarch, E., Taylor-Steele, S. \& Cumpston, A. (2000). Women in IT - What are the barriers? Retrieved April 7, 2003, from http://www.detya.gov.au/iae/analysis/womeninit.htm

Reicks, R. (2001). How to ensure that knowledge is power. The Journal of Business Strategy, 22 (4), 32-35.

Sheard, J., Lowe, G. \& Markham, S. (2001). Educating students in IT course options: An impact evaluation. Proceedings of the International Conference on Computers in Education, Seoul, Korea.

Standley, J. \& Stroombergen, L. (2001). 21st Century women and understanding the future research report, University of Nottingham Research Report. Retrieved February 17, 2003 from, http://www.eskills.com/cgi-bin/cms.pl/95

Stylianou, A. C. \& Kumar, R. L. (2000). An integrative framework for IS quality management. Communications of the ACM, 43 (9), 99-104.

Swanson, E. B. (1997). Maintaining IS quality. Information and Software Technology, 39, 845-850.

Trauth, E. M. (2002). Odd girl out: An individual differences perspective on women in the IT profession. Information Technology \& People, 15 (2), 98-118.

Vandenbosch, B. \& Higgins, C. A. (1995). Executive support systems and learning: A model and empirical test. Journal of Management Information Systems, 12 (2), 99-131.

Vidgen, R., Wood-Harper, T. \& Wood, R. (1993). A soft systems approach to information systems quality. Scandinavian Journal of Information Systems, 5 (Aug), 97-112.

von Hellens, L. A. (1997). Information systems quality, versus software quality: A discussion from a managerial, an organisational and an engineering viewpoint. Information and Software Technology, 39, 801-808.

Young, J. (2002). Women in IT Tasmania: Increasing the participation of women in information, communication technology careers. Retrieved March 22, 2003 from, http://www.intelligentadvantage.net.au/documents/292.pdf

Young, J. (2003). The extent to which information technology careers fulfil the career ideals of girls. Australian Journal of Information Systems, 10 (2), 115-125.

\section{Biography}

Kaylene Clayton is a Ph.D. candidate in Information Systems at Griffith University. She completed a degree in Internet Computing in 2002, for which she was awarded the Internet Computing Medal for highest achieving graduate. In 2003, she completed an IT Honours degree on recruitment issues in pre-tertiary IT education and was awarded the Griffith University Medal for academic excellence. Currently, she is involved in the development and implementation of a mentoring project to encourage local high school girls into science and IT education and career paths. She also continues to be involved in other mentoring projects aimed at recruitment of girls into ICT education and careers. Her research interests include gender and IT education, culture in teaching and learning in primary, secondary and tertiary learning environments. 